\title{
Motivating Online Learning: The Challenges of COVID-19 and Beyond
}

\author{
Thomas K. F. Chiu ${ }^{1}$ Tzung-Jin Lin ${ }^{2} \cdot$ Kirsti Lonka ${ }^{3}$
}

Published online: 28 April 2021

(C) De La Salle University 2021

\section{Introduction}

The COVID-19 pandemic has greatly impacted students' opportunities to learn worldwide. Students and teachers have been forced to shift from traditional classrooms to emergency online / remote learning. They face key challenges in adapting practices away from a focus on face-toface learning to an online learning environment mediated by various forms of technology. The pandemic reveals the urgent need to augment the educational system's technological infrastructure, expand the teachers' pedagogical expertise and the students' learning repertoire. Under the circumstances, researchers and practitioners should carefully reconsider the role of teachers, students, as well as the technological environment for online learning and put ongoing efforts to adequately address the underlying epistemological basis of education (Tsai et al. 2013). These emerging challenges have never been apparent during this critical period of time. Hence, it is urgent and crucial for researchers to reflect and improve the current practices of online learning and teaching through appropriate designs and evidence-based strategies for the time being.

Online learning also heavily relies on the students' ability to make meaning through assuming agency in learning, initiating and sustaining meaningful multimodal communications, and developing conceptual and epistemic understanding through active engagement with digital resources (Hartnett, 2016). In such online contexts, the

Thomas K. F. Chiu

tchiu@cuhk.edu.hk

Chinese University of Hong Kong, Hong Kong, China

2 National Taiwan Normal University, Taipei, Taiwan

3 University of Helsinki, Helsinki, Finland

critical role of students' self-regulation, motivation, and positive learning dispositions are accentuated (Chiu \& Hew, 2018). Although a substantial number of studies have encompassed these relevant issues in the field of educational technology, research evidence on how to appropriately adapt pertinent learning and motivational theories to design effective and sustainable online pedagogy in a complex, multifaceted, and even situational online learning environments are still relatively under-investigated.

A broad range of motivational theories derived from motivation research such as self-determination theory (SDT) (Ryan \& Deci, 2020), expectancy-value theory (Wigfield \& Eccles, 2000), achievement goal theory (Senko et al. 2011), and control-value theory (Pekrun, 2017) have been widely applied to understand the contextual and psychological factors that optimize students' learning and engagement. These relevant theories have been successfully applied to understand the underlying environmental and psychological factors that affect learners' motivation, engagement, and learning. When pedagogical design adequately addresses these needs, students are actively motivated to engage in learning tasks.

However, the aggregated stress and anxiety from the pandemic may easily demotivate and disengage student learning as prior studies have highlighted that negative emotions may inhibit learning (Pekrun et al. 2017). Although applying various motivational theories to traditional face-to-face environments has proven to be a productive undertaking (e.g., Lazowski \& Hulleman, 2016), little attention has been paid to how existing motivational theories can be adapted to understand how to optimize online learning or student engagement within technology infused learning contexts (Chiu, 2021; Hsu et al., 2019). This is a critical and urgent gap that cannot be ignored given the growing need for online learning in light of the pandemic. In addition, how student motivation can be 
build/leverage upon to sustain prolonged collaborative online meaning making is also an essential dimension that needs attention.

Given that the pandemic is evolving into a unique combination of public health crisis, social isolation, and economic recession that causes varying levels of anxiety and stress, we believe that the accepted papers would contribute new insights on how to leverage motivational theories to optimize online learning based on existing ongoing efforts and experiences gained from the pandemic. They also facilitate our discussions on how to rethink education to prepare teachers and students for technology infused learning during crisis period and beyond.

\section{Overview of the Nine Papers}

This special issue consists of nine empirical studies conducted in different countries and regions including China, Hong Kong, South Korea, Taiwan, Japan, Singapore and the USA. Six of them deal with student remote learning, and the other three concern teacher remote teaching, during the pandemic. The first paper is Lin's Taiwanese study. He used three prominent motivation theories related to selfregulated learning - expectancy-value, achievement goal, and social cognitive - to understand university students' motivations by examining the changes in their values and goals of online learning tasks. He developed and validated a COVID-19 Online Learning Motivation (COLM) questionnaire, and collected 558 students' online motivation before and after the outbreak of the pandemic. His study suggests that the pandemic has impacted on how the students value the personal relevance and the future expected returns of adopting online learning. Besides, the gaps between students' ideal and actual motivations may need to be proactively attenuated before the implementation of online learning.

The next three papers used the Structural Equation Modelling technique to examine their proposed research models driven from different theories of motivation, and aim to identify factors influencing students to learn remotely or online in China. The second paper, by Zhou, Chai, Jong and Xiong used SDT and a social cognitive perspective as a framework to investigate how perceived relatedness with instructors and classmates influence online self-regulated learning, perceived learning gains, and satisfaction. They analyzed self-reported survey data from 572 undergraduate students from a teacher education university in Southwest China, and found that relatedness had effects on perceived learning gains and satisfaction mediated by online self-regulated learning. They conclude that teachers can promote students online self-regulated learning by building a learning community and designing collaborative learning activities. The third paper, by Lian, Chai, Zheng and Liang, recruited 529 nonEnglish major students from a comprehensive university in northern China, and examined their model regarding the intricated relationships among the perceptions of meaningful learning such as self-directed learning, collaborative learning, self-efficacy. The results revealed that student perceived authentic language learning has a strong relationship with their English self-efficacy. This relationship can be mediated by collaborative, but not self-directed learning. These findings suggest that online collaborative learning opportunities appeared to be more pronounced for students when learning alone at home, and structuring authentic language learning with self-directed and collaborative learning is very important for blended learning. The fourth paper conducted by Lin, Jin, Zhao, Yu and Su, used switching behavior to explain student initial motivation (behavioral intention) in transiting face-to-face to online learning. They examined their proposed Push-Pull-Mooring model to understand the influence of habits and switching costs on student motivation to the harsh transition. Their results showed that the push effects (perceived security risk, learning convenience, and service quality), pull effects (usefulness, ease of use, teacher's teaching attitude, task technology fit), and mooring effects (switching cost, habit) can predict the transition intention. The findings suggest that teachers should take these relevant factors into account when accommodating students into a new online learning environment.

The fifth and sixth papers aim to understand what and how to design effective online tasks to constantly motivate students in learning. The fifth paper, by Lee, So, Ha, Kim, and Park, conducted an experimental study to examine the patterns of students' academic emotions and facial expressions detected in asynchronous video-based learning. They used Ekman's Facial Action Coding System to analyze the recorded video data collected from 25 Korean students, and analyzed interview data to understand the plausible explanations for students' negative emotions. This paper suggests how to detect and intervene in potential issues associated with student motivation and affective states. The sixth paper, by Ismailov and Ono, used expectancy-value, SDT and the Attention Relevance Confident Satisfaction (ARCS) model to identify the design characteristics of the online tasks assigned to 80 Japanese first year undergraduate students. Their inductive content analysis revealed that student motivation was strongly associated with student autonomy, social interaction, personal interest, and practical utility of the tasks. They suggest that teachers should pay more attention to the motivational effects of the designed instructional materials and assignments. 
Teacher motivation and capacity have emerged as the top priority in remote learning. The last three papers are qualitative studies and concern how teachers teaching in different educational settings. The seventh paper, by Moorhouse and Kohnke, used SDT as framework to interview university teachers in Hong Kong and identify two distinct teacher groups as either Thriving or Surviving. The results showed that the Thriving teacher group gained new instructional skill as the online teaching reinvigorated their teaching, and the Surviving group questioned their ability to teach because they felt isolated, struggled, and unsatisfied. The eighth paper, by Lambert, identified challenges a special education teacher from California faced when teaching mathematics to students with disabilities. An inductive thematic analysis revealed that one of the biggest challenges was supporting students with productive struggle in remote teaching. The findings suggest that fostering student engagement in mathematical problem-solving require considering emotional and affective dimensions of learning and coaching students and families in self-regulation strategies. The last paper, by Tay, Lee and Ramachandran, investigated how to design effective online home-based lessons for elementary and secondary student engagement. They adopted a ground-up thematic analysis to analyze interview data from elicit eight Singapore mathematics teachers. The findings suggest five design components including student engagement, technology, teacher professional development, social networking platforms and self-directed learning for the effective online lessons.

In sum, the major themes that emerged for the above studies seem to be motivation, socialization, and self-directedness. While these are familiar themes in educational research, the pandemic has greatly enhanced its importance in that without sufficiently strong pedagogical designs in these aspects, and the building of students' capacities and repertoires in these areas, learning will virtually grind to a complete stop.

\section{Challenges and Future Development}

The current pandemic is catalyzing a global debate on how knowledge, education and learning need to be reimagined in a world of increasing complexity, uncertainty, and precarity. The papers in this special issue raise 8 challenges that are pertinent in the times of the COVID-19 pandemic and beyond. We summarize the challenges raised and suggest future development as follows; therefore, hope they can facilitate discussions among researchers and practitioners on how to rethink education and shape the future of learning and teaching.
1 Attending to initial and maintaining student and teacher motivation for the emergency transition from face-toface to online (remote) learning. Understanding the motivational process from the initial arousal of the motivation to the sustained motivation of unfamiliar and sudden environments is necessary.

2 Preparing students for future learning. Most current studies suggest self-directed and collaborative learning as prerequisite skills for online instruction. Using online technology-assisted environments to foster the digital skills needs to feature more strongly in future research, i.e., nurture the skills and cultivate selfefficacy from various aspects during online learning.

3 Addressing the psychological needs of students in designing online learning. Previous studies related to online learning give primacy to autonomy and competence support for cognitive development (Chiu, 2021). Future studies should pay more attention to relatedness support and emotional development for student wellbeing.

4 Promoting technology-supported social and collaborative environments for peer mutual support. Current online learning studies highlight the importance of collaborative learning need to add specifically mutual peer support and social presence (Sormunen, 2020).

5 Enhancing teacher's design beliefs and efficacy for applying theories in motivating students. Currently, there are many theories and principles for better engaging students in online environments (Chiu et al., 2020; Ryan \& Deci, 2020); however, teachers may not able to execute the theoretical ideas in teaching. To bridge the gaps between theory and practice, teacher professional development program should encourage teachers to operationalize and implement what they learned from theories to experience the benefits, rather than telling them what the theories and principles are.

6 Supporting teacher wellbeing. Discussions about teacher wellbeing is overlooked as a 'nice to have' rather than as essential, and is often dominated by negative mental health. Wellbeing is not only essential to cope with negative situations, but also encompassing ideas such as job satisfaction and good relationships. It is important to think about and promote teacher wellbeing in a more holistic way (both negative and positive), which benefit both student and teacher learning. Recent research indicate that wellbeing may coexist with burnout symptoms, when teachers are devoted and simultaneously lack resources and work too hard. In a study by Salmela-Aro et al. (2019) Finnish teachers appeared to be very committed and engaged to their work, whereas many suffered at the same time some signs of exhaustion and inadequacy as a teacher. After 
COVID-19, it shall be important to follow and promote teachers' wellbeing in Asian countries as well.

7 Addressing equity and social justice concerns in learning with technology (Chiu \& Lim, 2020). Majority of educational studies related to the pandemic are conducted in mainstream schools or city areas. More studies are needed to investigate how to use technology to support minority groups such as students with special education need (inclusive education) and students living in rural areas (digital divide).

8 At a policy level, studies are also needed to reexamine research related to how the pandemic impact educational policies in Asian countries, while comparing with policies of more progressive countries (e.g., the United Kingdom, Australia), in order to better rethink what our future digital education should be envisioned.

Conclusively, the COVID-19 pandemic has resulted in school closures all across the world, triggering unprecedented challenges for education systems, and its impact on the world's education, particularly online learning, will be long lasting and resurging. It is clear that the future of education needs rethinking in many ways amid the pandemic. We truly hope this special issue will facilitate our discussions and research about the future of learning and teaching related to motivation.

\section{References}

Chiu, T. K. F. (2021). Applying the self-determination theory (SDT) to explain student engagement in online learning during the COVID19 pandemic. Journal of Research on Technology in Education, 1-17. https://doi.org/10.1080/15391523.2021.1891998.

Chiu, T. K. F., \& Hew, T. K. F. (2018). Factors influencing peer learning and performance in MOOC asynchronous online discussion forum. Australasian Journal of Educational Technology, 34(4), 16-28. https://doi.org/10.14742/ajet.3240.
Chiu, T. K. F., \& Lim, C. P. (2020). Strategic use of technology for inclusive education in Hong Kong: A content-level perspective. ECNU Review of Education, 3(4), 715-734. https://doi.org/10.1177/2096531120930861.

Chiu, T. K. F., Jong, M. S. Y., \& Mok, I. A. C. (2020). Does learner expertise matter when designing emotional multimedia for learners of primary school mathematics? Educational Technology Research and Development, 68, 2305-2320. https://doi.org/10.1007/s11423-020-09775-4.

Hartnett, M. (2016). The importance of motivation in online learning. In M. Hartnett (Ed.), Motivation in online education (pp. 5-32). Springer.

Hsu, H. C. K., Wang, C. V., \& Levesque-Bristol, C. (2019). Reexamining the impact of self-determination theory on learning outcomes in the online learning environment. Education and Information Technologies, 24(3), 2159-2174.

Lazowski, R. A., \& Hulleman, C. S. (2016). Motivation interventions in education: A meta-analytic review. Review of Educational Research, 86(2), 602-640.

Pekrun, R., Lichtenfeld, S., Marsh, H. W., Murayama, K., \& Goetz, T. (2017). Achievement Emotions and Academic Performance: Longitudinal Models of Reciprocal Effects. Child Development, 88(5), 1653-1670.

Ryan, R. M., \& Deci, E. L. (2020). Intrinsic and extrinsic motivation from a self-determination theory perspective Definitions, theory, practices, and future directions. Contemporary Educational Psychology. https://doi.org/10.1016/j.cedpsych.2020.101860.

Salmela-Aro, K., Hietajärvi, L., \& Lonka, K. (2019). Work burnout and engagement profiles among teachers. Frontiers in Psychology, 10, 2254.

Senko, C., Hulleman, C. S., \& Harackiewicz, J. M. (2011). Achievement Goal Theory at the Crossroads: Old Controversies, Current Challenges, and New Directions. Educational Psychologist, 46(1), 26-47.

Sormunen, K. (2020). From inclusive practices to personal strategies. Nordic Studies in Science Education, 16(2), 234-234.

Tsai, C.-C., Chai, C. S., Wong, B. K. S., Hong, H.-Y., \& Tan, S. C. (2013). Positioning design epistemology and its applications in education technology. Educational Technology \& Society, 16, 81-90.

Wigfield, A., \& Eccles, J. S. (2000). Expectancy-value theory of achievement motivation. Contemporary Educational Psychology, 25(1), 68-81.

Publisher's Note Springer Nature remains neutral with regard to jurisdictional claims in published maps and institutional affiliations. 